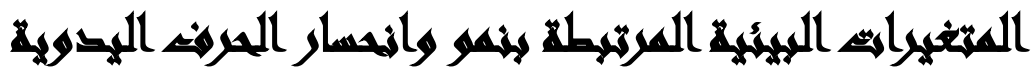

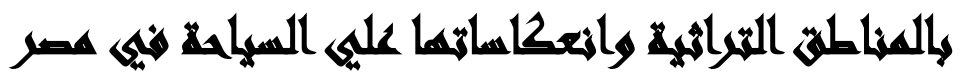

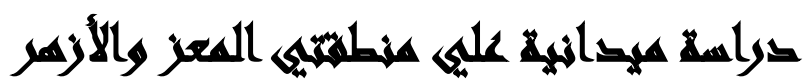

\section{$[1 \cdot]$}

ناجا عبد الحميد أبو النيل(')- أمل عبد الفتاح شمس الدين(؟)- نرمين خيري إبراهيم(r) أحمد فوزي علي المباح

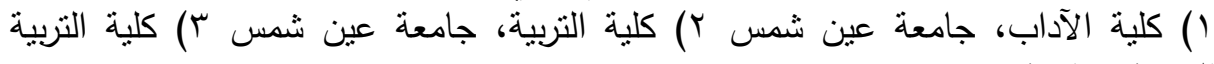

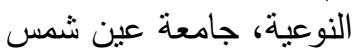

\section{المستخلئ}

ويسعى الباحثون من وراء اجراء البحث الى محاولة تحقيق عدة اهداف وهى التعرف

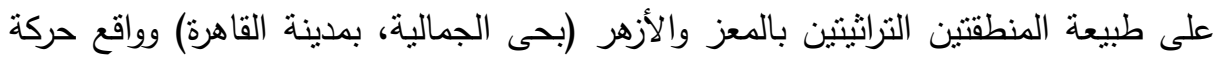

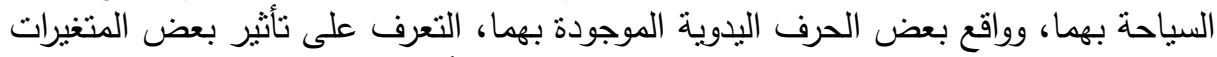

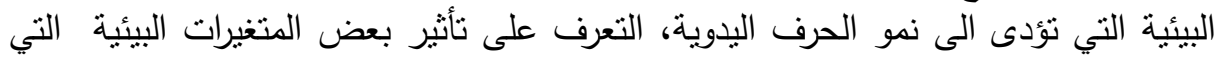

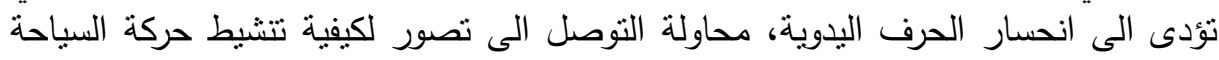

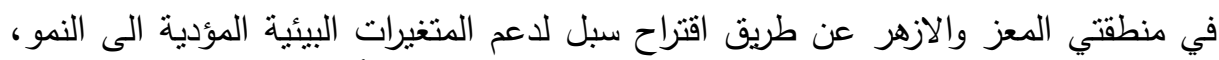

وتحجيم تلك المؤدية الى الانحسار وتدعيم الصناعات الحرفئ الحرفية من أجل التتمية المستدامة.

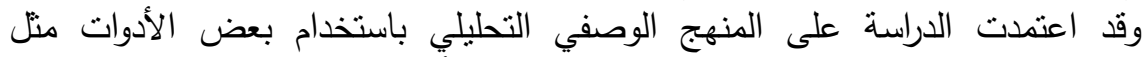

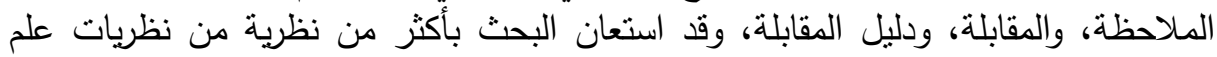

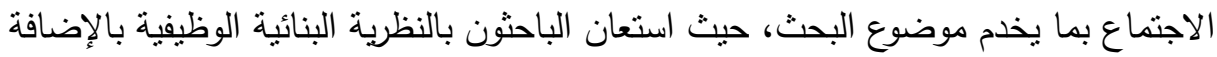

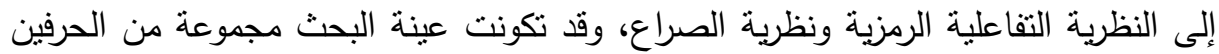

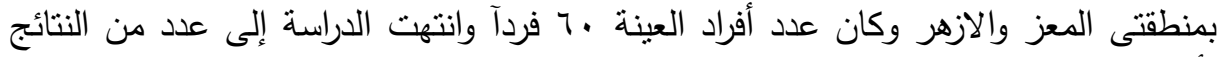

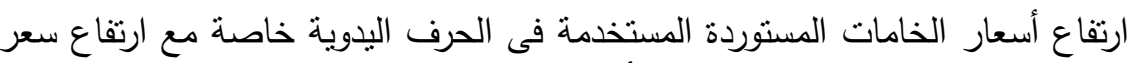

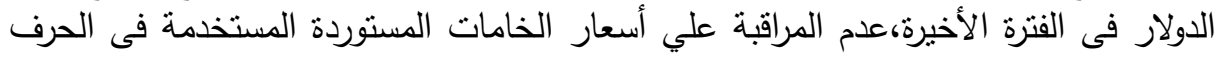

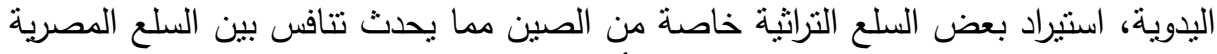

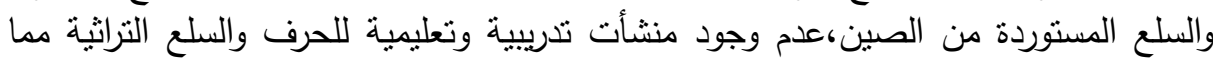

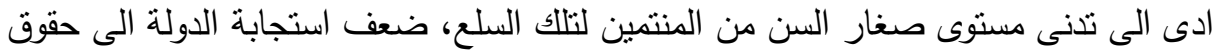

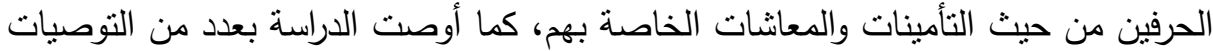

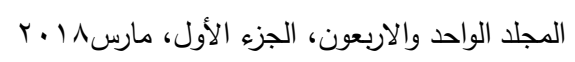


منها أنشاء جهة ما حكومية لمراقبة الإسعار والخامات الخاصة بالحرفة اليدوية التراثية

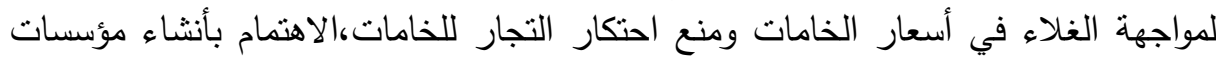

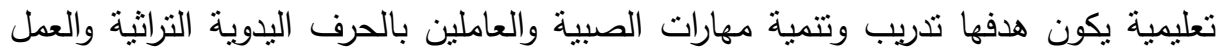

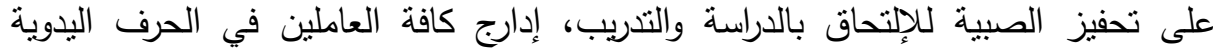
التراثية في نظام التأمينات والمعاثات والتأمين الصحى ورفع مستوى المعيشة.

\section{هتمهة}

يعتبر النشاط الصناعي للإنسان ظاهرة اجتماعية مرتبطة بظاهرة الاجتماع الانسانى

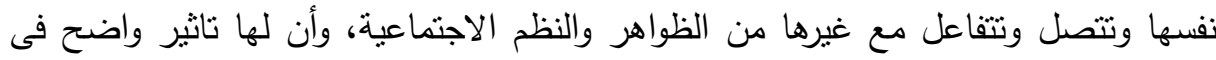

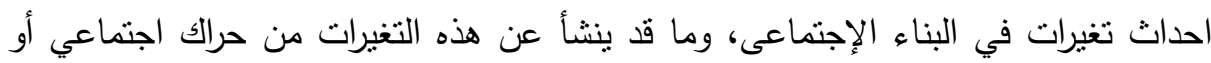

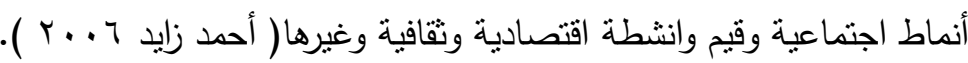
تتثير تحليلات اقتصادية واجتماعية لتجارب عالمية خلال العقدين الأخيرين إلى أن معظم الإقتصاديات التى اتخذت من الصناعات الحرفية ركيزة لها حققت إنجازات هائلة، وتحولت من قوى استهلاكية إلى قوة إنتاجية خلاقة، وان هذه الصناعات الحرفية لها انعكاسات

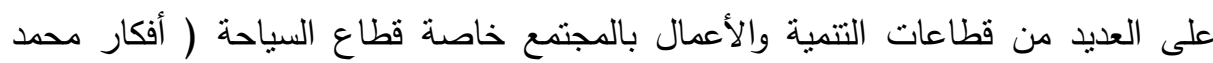

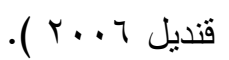

وتعانى تلك الصناعات مجموعة من المعوقات مرتبطة بعمليات التسويق، ونقص

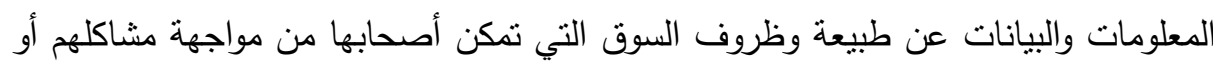
تساعدهم على التوسع في أعمالهم وتتفيذها، حيث إن أفق صاحب الصناعة الحرفية الثقليدية غالباً لا يمتد في كثثر من الأحيان لاكثر من شئون حرفته أو صناعته.

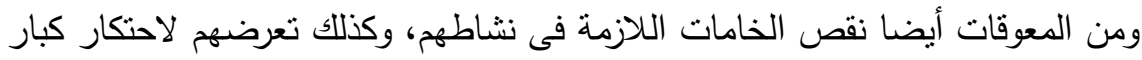
التجار وكذا البائعين في الإسواق المحلية الصغيرة، وعدم معرفتهم مصادر بديلة لهذه

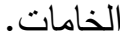

أضف على تلك المعوقات عدم وجود الخبرة الكافية لأصحاب هذه الحرف فى مجالات

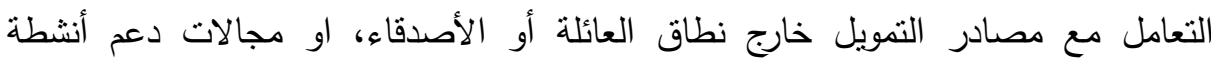

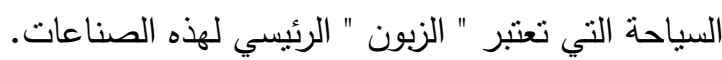

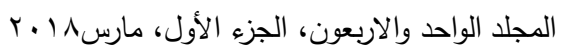


فطبيعة الصناعات اليدوية الحرفية التراثية في مجتمعاتها مرتبطة ببعض المتغيرات البيئية، وبالتالى يندرج ذلك على مجتمع البحث الراهن فى منطقتي المعز والأزهر لبحث الظروف الموضوعية المحيطة والمؤثرة بالحرف بحالات النمو والانحسار وتساهم هذه الدراسة في الوقوف علي المتغيرات البيئية مما يساعد في التوصل إلي توصيات ومقترحات نساعد هذه

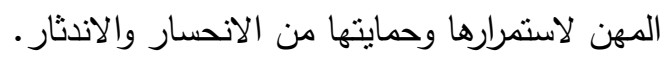

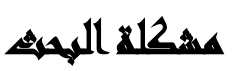

تتشير العديد من الكتابات الى ان الحرف البدوية الموجودة في المناطق التراثية تعانى في العالم عامة وفي مصر خاصة من عوامل ومتغيرات بيئية تؤثر عليها سلباً بالإنحسار وايجابياً

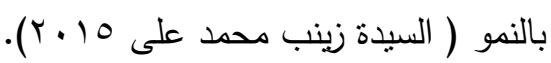
ومما لاشك أن ذلك يؤثز على السياحة في أى مكان في العالم وخاصة في مصر فلابد من المحافظة على الحرف كأسلوب مواجهة البطالة وتشتيل الحرفين ( فاطمة بسيونى الثناوى $\cdot(r \cdot s$

\section{أسئلا الهمهي}

السؤال الرئيسى: إلى أى مدى يمكن إيضاح الكيفية التى تتعكس بها المتغيرات البيئية المرتبطة بنمو وانحسار الحرف اليدوية التراثية على السياحة في مصر؟ إلى

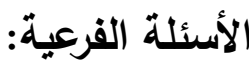

ثم. إلى أى مدى بمكن التعرف على طبيعة الحرف اليدوية التراثية بالمنطقتين التراثتين بالمعز

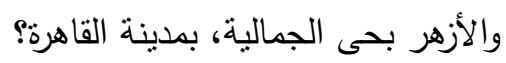

•• ما واقع حركة السياحة بالمنطقتين التراثتين بالمعز والأزهر (بحى الجمالية، بمدينة القاهرة)

هـ ما المتغيرات البيئية المرنبطة بنمو وانحسار الحرف اليدوية التراثية في مصر؟ •• إلى أى مدى يمكن تيان اثر للمتغيرات البيئية المرتبطة بنمو وانحسار الحرف اليدوية

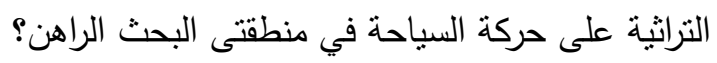


ها ما إمكانية وضع تصور لكيفية دعم المتغيرات البيئية المؤدية الى النمو، وتحجيم تلك

$$
\text { المؤدية الى الانحسار }
$$

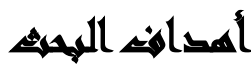

• التعرف على طبيعة المنطقتن التراثتين بالمعز والأزهر (بحى الجمالية، بمدينة القاهرة) وواقع حركة السياحة بهما، وواقع بعض الحرف اليدوية الموجودة بهما.

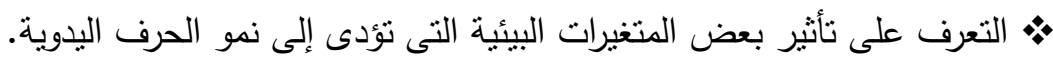

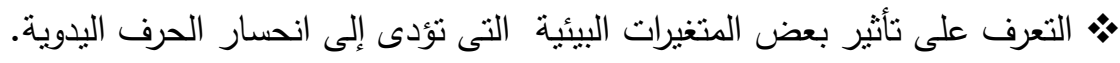

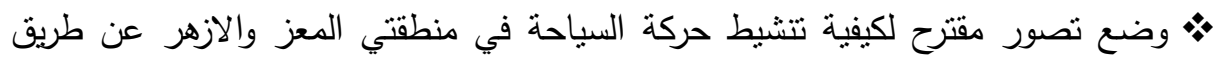

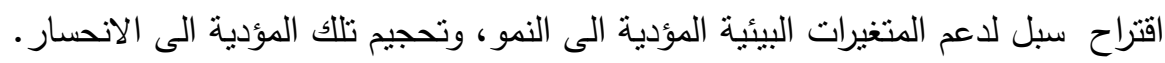

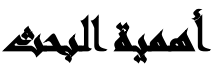

يهنم البحث بدراسة المتغيرات البيئية المرتبطة بنمو وانحسار الحرف اليدوية بالمناطق

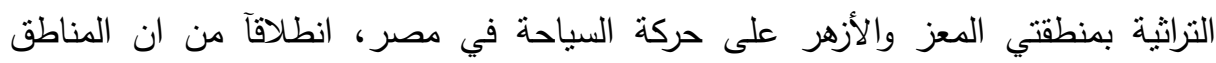

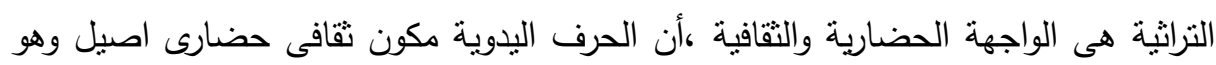
ما يدعو لبحث هذه المتغيرات وتاثيرها على المناطق التراثية وعلاقة ذلك كله بالسياحة

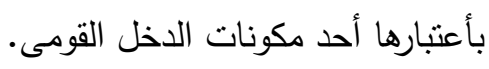
الجهات المستفيدة من هذا البحث: ( وزارة الصناعة، وزارة التجارة الداخلية، وزارة الثقافة، وزارة السياحة، الغرفة التجارية، الهيئة العامة للإستعلامات، مركز المعلومات ودعم

\section{مصطالماهو المهيد}

المتغيرات البيئية: يقصد بها المكان الذى يعيش فى إطاره الفرد، وبناء على ذلك فإن البيئة بمعناها هى الحى أو المنطقة أو المدينة السكنية لما لها من نأثير على تثلى تثكيل حياه الأفراد الذين يعيشون فى نطاقها.

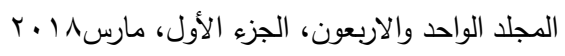


الحرف اليدوية: هى نشاط انتاجى يمارسه فرد أو جماعة صغيرة العدد داخل مكان ثابت وهى ورشة صغيرة، وتعتمد على استخدام المهارة اليدوية.

المناطق التراثية: هى المناطق ذات الملامح التاريخية المتميزة عمرانيا ومعماريا سواء كانت الت إنهاء نشأتها فى العصور القديمة المختلفة كالعصور القبطية أو الإسلامية. السياحة: السياحة هى مجموعة التتقلات والأنشطة الناتجة عن حركة الإنسان وبعده عن الإنسانه موطنه الإصلى تحقيقاً لرغبة الإنطلاق الكامنة فى كل فرد.

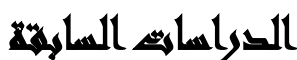

وفيما يلي عرض البحث لاربعة محاور نتاولت متغيرات البحث وهى: ( المتغيرات

البيئية.، المجتمعات الحرفية، السياحة، المناطق التراثية ).

المحور الأول: اهتم بالمتغيرات البيئية.

دراسة المهدي محمد علي • 1 · ب: تتمية وتطوير الصناعات الصغيرة وأثرهاعلي المجتمعات

العمرانية دكتوراه، قسم الهندسة البيئية، معهد الدراسات والبحوث البيئية، جامعة عين شمس. دراسة سهير حسين إبراهيم الدمنهورى 1 ـ ب : الصناعات التقليدية بين الأصالة والمعاصرة

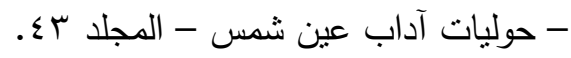
المحور الثاني: اهتم بالمناطق التراثية

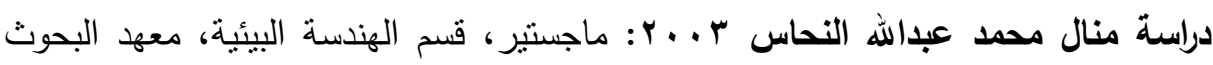
والدراسات البيئية، جامعة عين شمس ـ دراسة العمران في المناطق ذات القيمة التاريخية وتأثير البيئة الاجتماعية بالقاهرة الفاطمية.

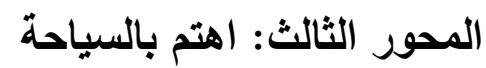
دراسة هبه الله احمد عوض شاهين V ... ץ: تمية السياحة الحضارية فى محافظة القاهرة، ماجستير، غير منشورة، دراسات سياحية، كلية سياحة وفنادق، جامعة حلوان • 
دراسة جيرمين حسين الثهير بنبيل عبد الكافي V . . ץ: ماجسنير، دراسات سياحية، كلية سياحة و فنادق، جامعة حلوان •تفعيل تسويق التراث الإسلامي لتتمية الحركة السياحة الثقافية الوافدة إلى مصر.

\section{المحور الرابع: اهتم بالمجتمعات الحرفية}

دراسة السيدة زينب محمد علي 10 ـب: مشكلات البيئة الإجتماعية والفيزيقية للعاملين بالمهن الحرفية، ماجسنير، قسم العلوم الإنسانية، معهد البحوث والدراسات البيئية، جامعة عين شمس. دراسة شريف محمدعوض 10 • ب : أثر الركود الإقتصادى في الصناعت الحرفية بمحافظة

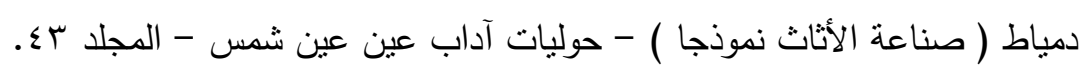

\section{الإطال النظلرى للهيه}

تتاول دراسة الصناعات الحرفية وخاصة أثز الركود الإقتصادى عليها، الكثير من

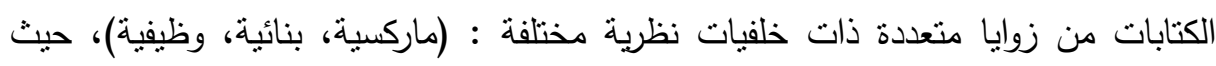
يتضح ان قطاع الصناعات الحرفية أكثر عرضة للتأثر بأزمة الركود الإقتصادى. وفى هذا الصدد، يشير المنظور الوظيفى إلى الدور الذى يلعبه النظام في البناء

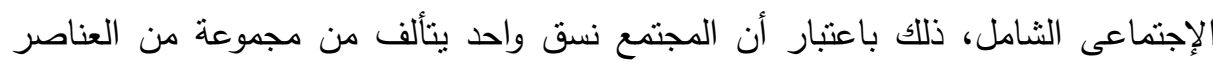

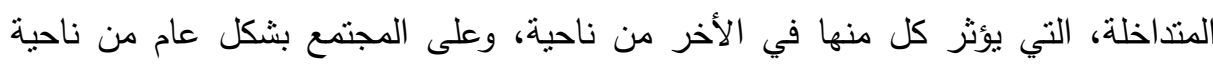
أخرى. كذلك ينهض المنظور الوظيفى على فكرة أن الوقائع والأحداث الاجتماعية يمكن تفسيرها

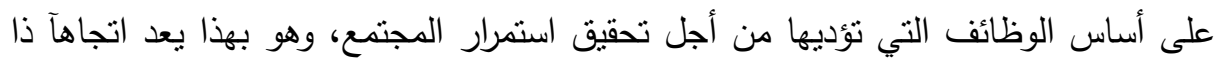

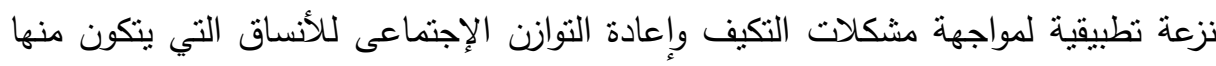


فوفقآ للمنظور الوظيفى فإننا نفهم أن الركود الإقتصادى في الصناعات الحرفية من حيث

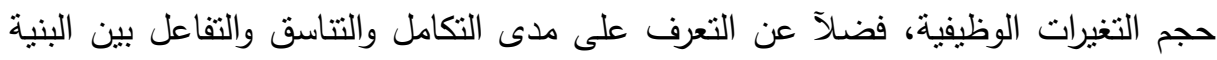
الحرفية والبنية الاقتصادية والإجتماعية في المجتمع، فمن المهم دراسة الأدوار الحرفية في

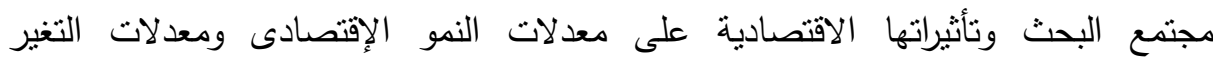
الإجتماعى، هذا فضلآ عن التعرف على العلاقات التي تحكم التفاعل بين الحرفيين أنفسهر والبينية الاقتصادية عموماً.

أما "المنظور البنائى"، فيشير مفهموم البناء إلى مجموعة من العناصر بينها علاقات

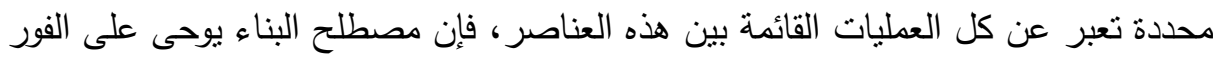

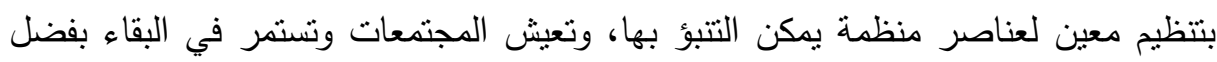
هذا التتظيم الذى يعرف بمقتضاه كل عضو من أعضاء الجماعة ما ينبغي عليه القيام به،

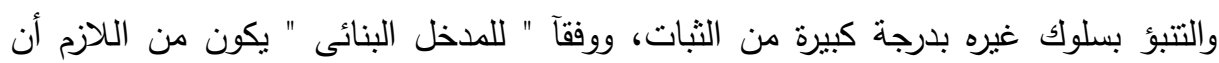

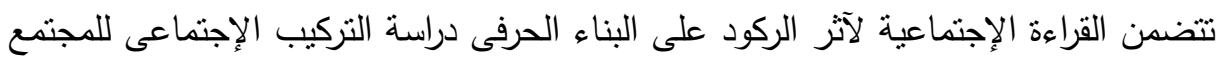
الذى تتركز فيه الحرف بكثافة، وذلك بأن يتعرف على حجم الحرفيين، وتوزيعهم وكثافاتهم لإنه وتركيبهم الطبقى، وذلك حتى نتمكن وفق هذا المنظور من الوقوف على التغيرات البنائية التي طرأت على الصناعات الحرفية في مجتمع البحث.

أما " المنظور الماركسى "، فيفسر سبب الدورات الاقتصادية بالتتاقضات الرئيسية التى التى

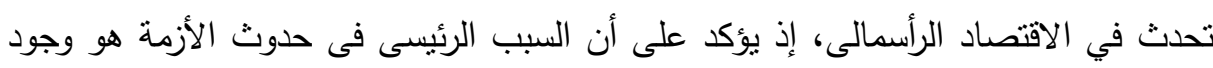

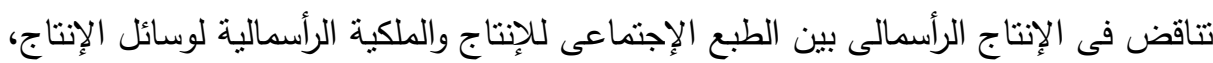

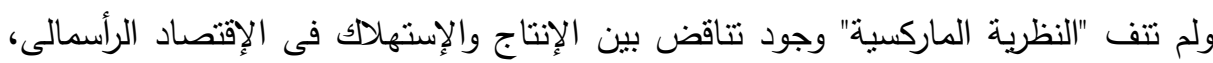

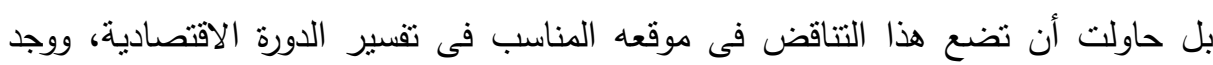

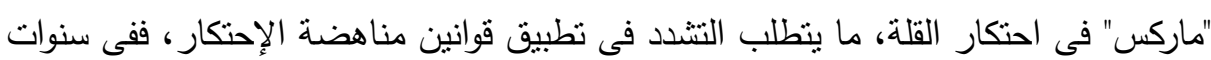

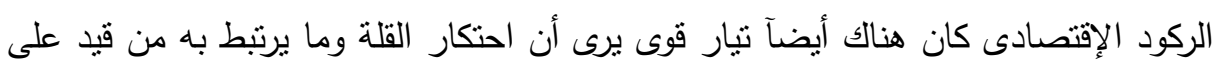

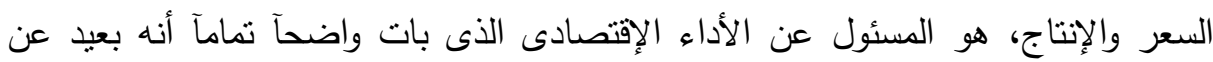


الأداء الأمتل، يضاف إلى ذلك أن احتكار القلة لا ينفق من ناحية المبدأ مع العدالة الاجتماعية.

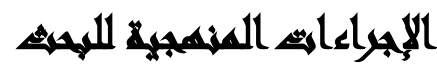

المنهج المستخدم: استعان الباحثون في معالجة موضوع البحث بمدخل المسح الإجتماعى باستخدام العينة ومستفيدا من معطيات المنهج الوصفي لرصد ووصف وتحليل أبعاد ظاهرتي (نمو وانحسار ) الحرف اليدوية بمنطقني المعز والازهر التراثنتين.

أدوات البحث وتوصيفها: يتجه الباحثون الى مجتمع البحث بادوات بحثية محددة وملائمة

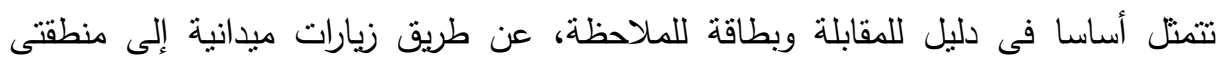
البحث ( الأزهر والمعز ). دليل المقابلة: (يحتوى على مجموعة من الأسئلة أو العبارات المكتوبة يجيب المبحوث عنها تدور حول محاور البحث الرئيسية). بطاقة ملاحظة: يتجه الباحثون إلى استخدام هذه الأداة لجمع البيانات عن طريق ملاحظة الباحثون لمجتمع البحث، وليسجل الباحثون ملاحظاتهم عن طبيعة العلاقات الداخلية بالورشة والخارجية خارج نطاق الورشة لمفردات العينة.

العينة وحجمها: وتتمنل في العاملين بالحرف اليدوية: حيث يمثل الحرفيون العاملون فى لئئ

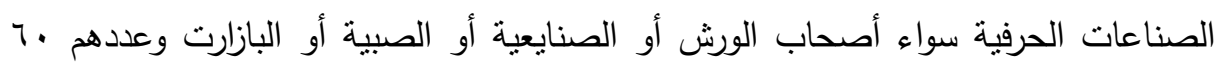
مفردة.

فترة ونطاق التطبيق الميدانى: نم إجراء البحث المبداني فى المناطق التراثية بمنطقتي المعز والأزهر حى الجمالية فى محافظة القاهرة أستغرقت الزيارات الميدانية من ناريخ آجناء

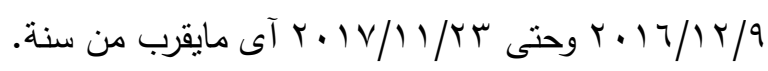

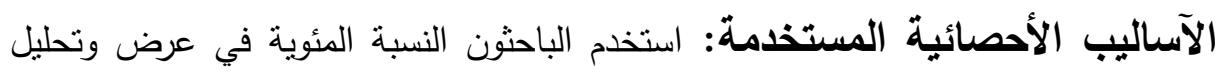




\section{عرض جداول البيانات الإحصائية:}

جدول( (1): تفريغ مشكلات العاملين بالحرف اليدوية

\begin{tabular}{|c|c|c|}
\hline ك & بند & ? \\
\hline r. & عدم وجود سياحة داخلية وخارجية & 1 \\
\hline YI & ارتفاع أسعار الخامات & r \\
\hline 0 & عدم وجود معارض محلية ودولية & $\mu$ \\
\hline 14 & عدم وجود صبية عدم وجود مدارس تدريب لهم & $\varepsilon$ \\
\hline$\varepsilon$ & آحتكار المادة الخام & 0 \\
\hline$\Lambda$ & زيادة الإستيراد من الصين وغيرها & 7 \\
\hline 1 & الإزهاب والظروف الآمنية & $\mathrm{V}$ \\
\hline$\Lambda$ & عدم وجود تأمينات ومعاشات & $\Lambda$ \\
\hline 0 & تراكم المخزون وتوقف دورة رأس المال & 9 \\
\hline$\varepsilon$ & دخول الميكنة والآلات الحديثة في مجال الحرف & 1. \\
\hline 7 & عدم توراث الحرف للابناء & 11 \\
\hline 1. & آغلاق معظد الورش لعدم الاهتمام بالحرفيين & TY \\
\hline $\bar{Y}$ & لا توجد رقابة من الدولة للأسعار & $\pi$ \\
\hline$T$ & لا توجد مشاريع حقيقية للشباب & T乏 \\
\hline r & كثرة المخالفات المالية على الورش & 10 \\
\hline 11. & & مج \\
\hline
\end{tabular}

يتضح من الجدول أنه يوجد تفاوت في مشاكل الحرفيين وعلى سبيل المثال أكثر

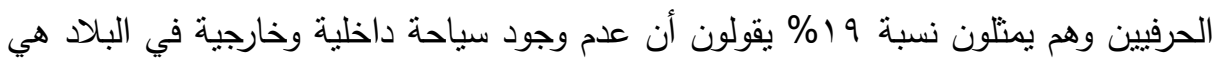

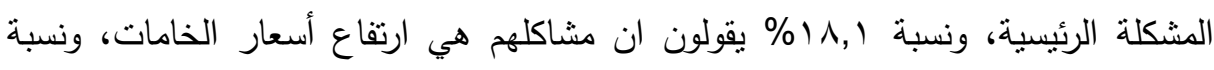

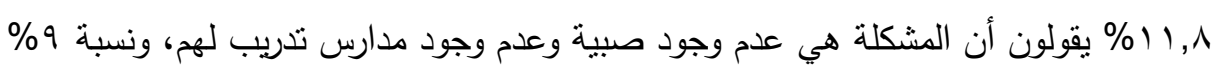

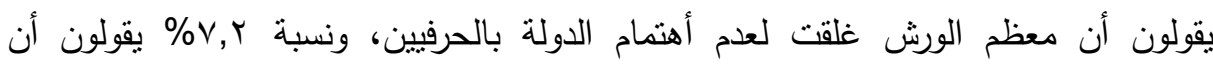

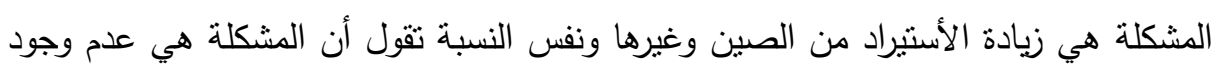

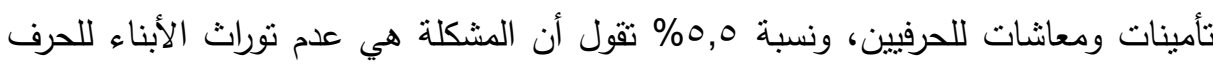

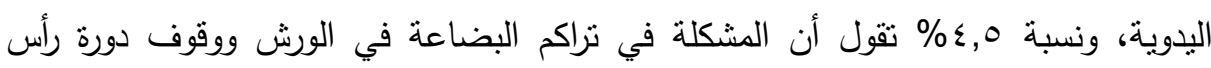

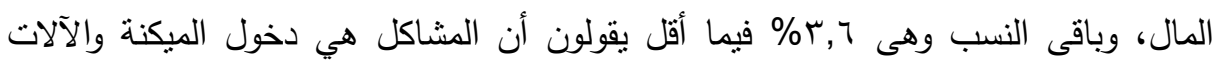
الحديثة الى سوق العمل اليدوى، ولا توجد رقابة على أسعار الخامات وكثر المخالفات المالية

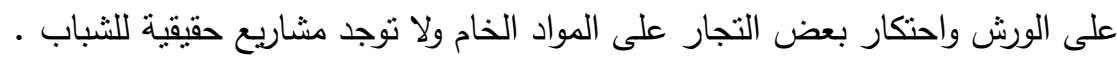

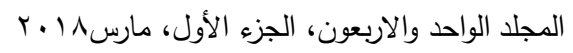


مجلة العلوم البيئية

معهز الدراسات والبحوث البيئية - جامعة عين شمس لهن

جدول(ץ): احتياجات العاملين بالحرف اليدوية من الدولة

\begin{tabular}{|c|c|c|}
\hline ك & بند & P \\
\hline 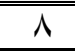 & عمل نأمينات ومعاشات للحرفيين & 1 \\
\hline$\wedge$ & أقامة معارض محلية ودولية & r \\
\hline r & المساعدة على الإزمات & r \\
\hline 9 & غلق باب الأستيراد & $\varepsilon$ \\
\hline 9 & القاء الضوء على مهارة الحرفيين في عن طريق الاعلام & 0 \\
\hline 1 & دعم صناعة الفوانبس المصرية مرة اخرى & 7 \\
\hline$\Lambda$ & أهتمام الدولة بالرعاية الصحية للحرفيين & $\mathrm{V}$ \\
\hline Y) & تخفيض أسعار الخامات وعدم احتكارها ومراقبة الأسعار & $\Lambda$ \\
\hline 11 & العمل على تتشيط السباحة & 9 \\
\hline 9 & عمل معاهد ومدارس تتكريب للصبية & 1 . \\
\hline r & تسويق المنتجات المتراكمة & 11 \\
\hline 1 & تقليص العمل بالتكنولوجيا & IT \\
\hline Y & القضاء على التوكوتلك & $1 \pi$ \\
\hline $\bar{Y}$ & الغاء القيمة المضافة & Is \\
\hline 1 & القضاء على الإرهاب & 10 \\
\hline 1 & عمل مشاريع حقيقة للشباب & 17 \\
\hline 0 & تقنين و وتخفيف العقوبات على الورش الصغيرة & $1 \mathrm{~V}$ \\
\hline $1 \cdot 1$ & & مج \\
\hline
\end{tabular}

يتضح من الجدول أنه يوجد تفاوت في احتياجات العاملين بالحرف اليدوية وذلك يشير

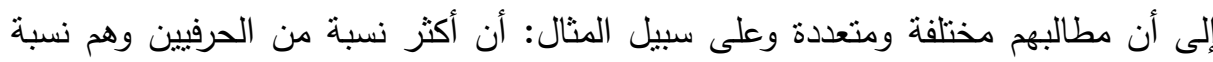

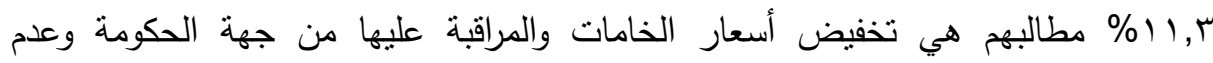

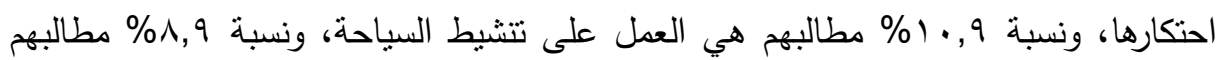
هي غلق باب الإسنتيراد ومنلهم يطالبون بألقاء الضوء على مهارة الحرفيين عن طريق الإعلام

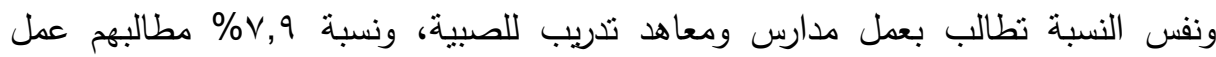

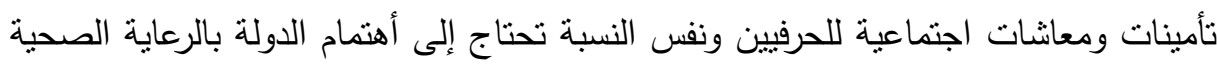

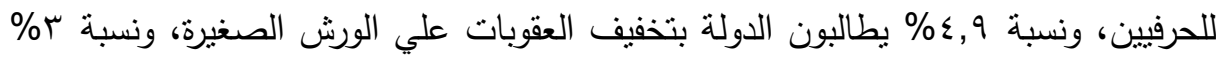

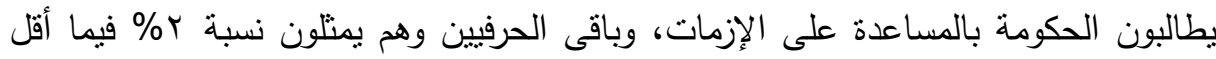

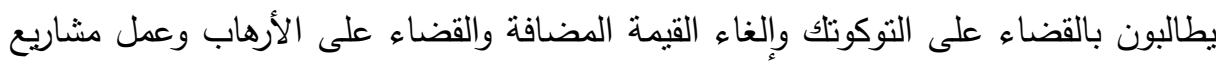
حقيقية للثباب وتقليص العمل بالتكنولوجيا للحرف اليدوية. 


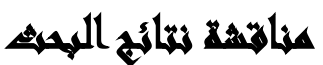

في ضوء الأسئلة التي طرحها البحث، والدراسات السابقة المرجعية، وما انتهى البحث إليه من نتائج يمكن مناقثتها من خلال المحاور التالية:

• • السباحة ومسؤليات الدولة تجاه قطاع الحرف اليدوية التراثية. •م المتغيرات البيئية. محور اهتم بأدوات وعلاقات الإنتاج والاحتكار واليات السوق. • • المجتمعات الحرفية بتوارث الحرفة والتتريب ومؤسساته. •. (المناطق التراثية.

\section{() المحور الأول: اهتم بالسياحة ومسؤليات الدولة تجاه قطاع الحرف اليدوية} التراثية: اتفق البحث الراهن مع كل من دراسة جيرمين حسين، دراسة هبه اله احمد الهد

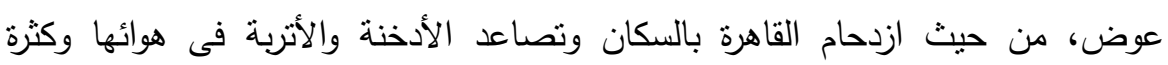
مضايقات السائحين بمناطق المزارات السياحية من قبل الباعة الجائلين والمنسولين

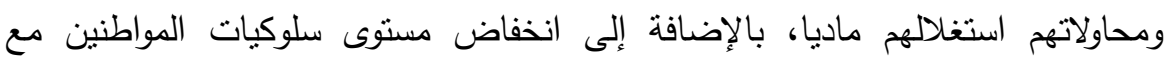

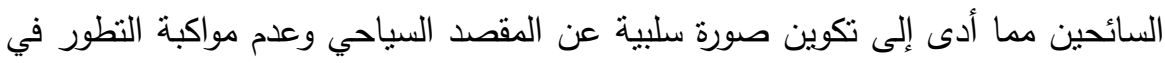
التتمية السياحية، وزيادة المشكلات المرتبطة بالبيئة الأساسية، بجانب عدم الرقابة الصحية الصناية

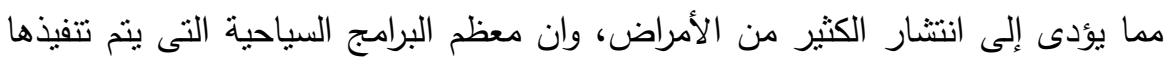

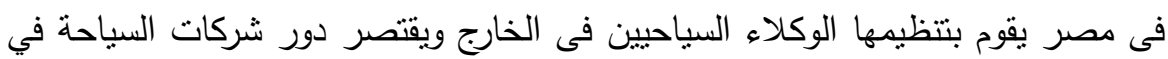

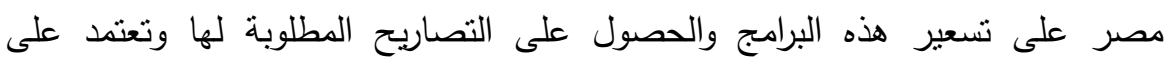
مجهودات وزارة السياحة وهيئة تتشيط السياحة في الترويج والتتشيط، ضعف ولفير استجابة

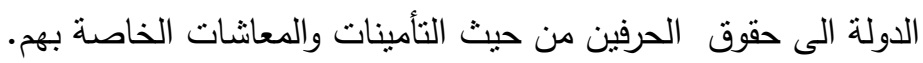

r) المحور الثاني: اهتم بالمتغيرات البيئية، ويأدوات وعلاقات الإنتاج والاحتكار واليات السوق: أتفق هذا البحث في نتائجه مع دراسة المهدي محمد على، حيث أسفرت النتائج عن مطالبة الدولة بتحديد نسبة من التوريدات الحكومية للمشروعات الحرفية التراثية

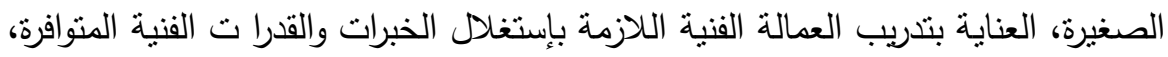

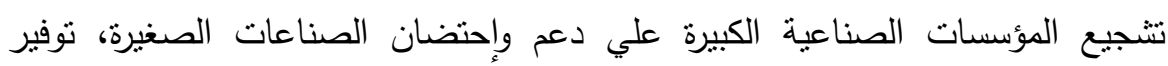

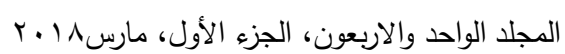


الألبات اللازمة لتحفيز هذه المؤسسات لمساعدة الثركات الصغيرة في تتمية منتجاتها وزيادة فرص التصدير أمامها.

وتميز البحث الحالي بالكثف عن اهم المشكلات التي يعانى منها الحرفيين بالحرف اليدوية التراثية، واتفقت معه دراسة سهير حسين إبراهيم الدمنهورى، بالكثف عن المشكلات

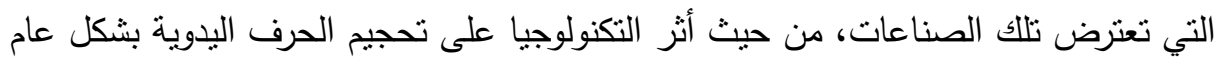
مما يؤثر على تتميتها في إطارها الثقافي، واستهداف الحفاظ على النمط الثقافي، ارتفاع أسعار الخامات المستوردة المستخدمة فى الحرف اليدوية خاصة مع ارتفاع سعر الدولار فى الفترة الأخيرة، عدم مراقبة أسعار الخامات المستوردة المستخدمة فى الحرف اليدوية، احتكار

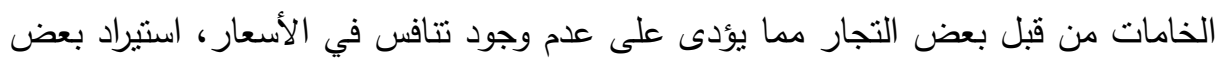
السلع التراثية خاصة من الصين مما يحدث تتافس بين السلع المصرية والسلع المستوردة، عزوف عن الإقبال على السلع التراثية المصرية وذللك لارتفاع اسعارها مقارنة بمثلها المستوردة

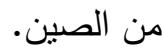

r) المحور الثالث: اهتم بالمجتمعات الحرفية وتوارث الحرفة وترقية الصبية والتدريب ومؤسساته: اتقق البحث الراهن مع كل من دراسة السيدة زينب محمد على، ودراسة شريف محمدعوض، في تحديد أهم المشكلات البيئية الاجتماعية للمهن الحرفية في حى الجمالية، ورصد أهمية منطقة الأزهر وشارع المعز في نتشيط السياحة والحفاظ على المهن التراثية اليدوية من الإنحسار والتعرف علي المتغيرات البيئية المرتبطة بنموها

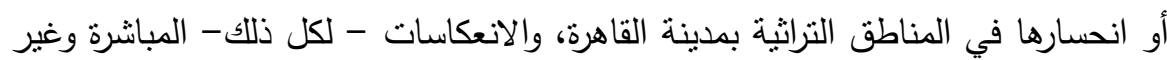

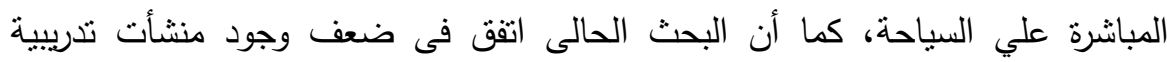
أوتعليمية للنشه وللصبية على الحرف اليدوية التراثية، كل ذلك ما ادى التى الى توقع تدنى التى

$$
\text { مستوى صغار السن العاملين بهذه الحرف. }
$$

كما تبين أن الركود الإقتصادى أثز سلباً بإحداث مشكلة تسويق المنتجات الحرفية

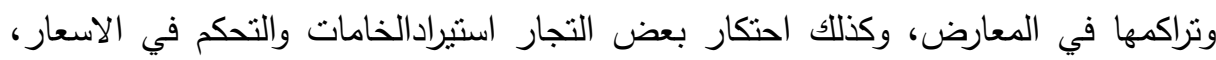
وعدم تدخل الدولة لحماية صغار الحرفيين.

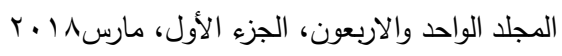


ع) المحور الرابع: اهتم بالمناطق التراثية: حيث تتفق دراسة منال محمد عبداله النحاس مع البحث الراهن في أن أسباب تدهور منطقة الجمالية أسباب إدارية وعمرانية واجتماعية وبيئية، كما اتفقا في ان البحث الميداني أظهر المشكلات التى يعاني منها

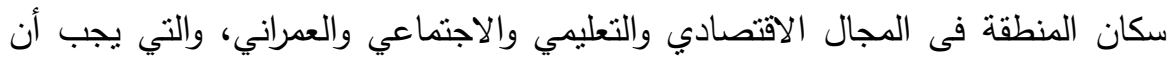
تؤخذ فى الاعتبار عند عمل مشاريع التتمية المتواصلة للمنطقة على مسنوى مشاريع

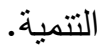

\section{اللموكياميت}

\section{كما أوصت البحث بعدد من التوصيات منها:}

• يوصى الباحثون بإنشاء جهة ما حكومية لمراقبة الإسعار والخامات الخاصة بالحرفة اليدوية اليدواية التراثية لمواجهة الغلاء في أسعار الخامات ومنع أحتكار التجار للخامات. • الاهتمام بإنشاء مؤسسات تعليمية يكون الهدف منها تدريب وتتمية مهارات الصبية والعاملين بالحرف اليدوية التراثية والعمل على تحفيز الصبية للإلتحاق بالدراسة والتدريب.

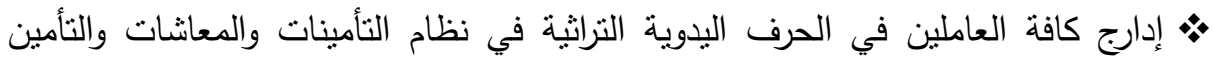

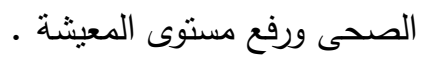

\section{المراجي}

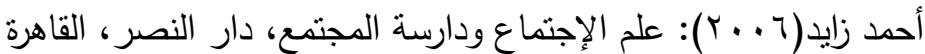

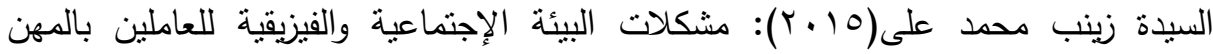
الحرفية، ماجستير، قسم العلوم الإنسانية، معهد البحوث والدراسات البئية البئية، جامعة عين شمس ماجسئر،

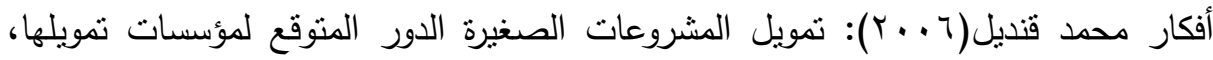

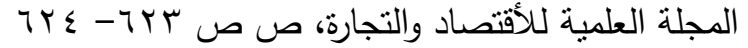

فاطمة بسيونى الثناوى: المحافظة على الحرف كأسلوب لمواجهة أزمة البطالة: دراسة حالة

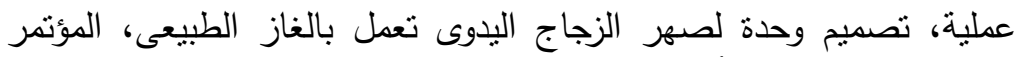

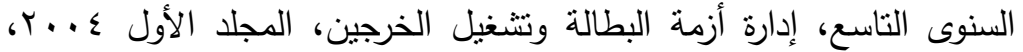
كلية التجارة، جامعة عين شس التمس البطال

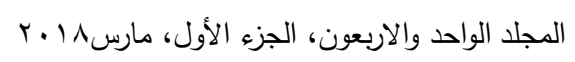


Duroy Q.M:( 2003), Culture,Environmental values \& Economic Grouth, essay in $\mathrm{PhD}$ (Development \& Ecological economics), Bensselare Polytechnic Institute .

Grigeli,Peter,Edward: (2005), The Effects of environment on commercial \& industrial property values , $\mathrm{PhD}$, Georgia state university.

Schwob William A: (1992), The Sociology of cities ,Prentice Hallince,.

\section{ENVIRONMENTAL VARIABLES ASSOCIATED \\ WITH THE GROWTH AND DECLINE OF \\ HANDICRAFTS IN HERITAGE AREAS AND THEIR \\ IMPLICATIONS FOR TOURISM IN EGYPT - FIELD \\ STUDY ON AL-MOEZ AND AL-AZHAR}

\section{Abu Neel, N. A. ${ }^{(1)}$; Shams El Din, Amal, A. ${ }^{(2)}$; Ibrahim, Nermin, K. ${ }^{(3)}$ and Ali, A. F.}

1) Faculty of Arts, Ain Shams University 2) Faculty of Education Ain Shams University 3) Faculty of Specific Education Ain Shams University

\section{ABSTRACT}

Research goals: The researcher seeks to carry out the current research to try to achieve the following objectives:

- .To recognize the nature of the two heritage areas in El-Azhar and Al-Azhar (Al-Gamaliya District, Cairo) and the reality of their tourism movement and the reality of some of the handicrafts in them.

- To recognize the effect of some environmental variables on the growth of handicrafts.

$$
\text { المجلد الواحد والاربعون، الجزء الأول، مارس^ا • r }
$$


ناجا عبد الحميد أبو النيل وآخرون

- To recognize the effect of some environmental variables on the decline of handicrafts.

- Trying to come up with a vision of how to activate the tourism movement in Al-Moez and Al-Azhar by proposing ways to support the environmental variables that lead to growth and to limit those that lead to decline.

The study relied on the analytical descriptive method using some tools such as: observation, interview, and in-depth interview manual.

The study has reached several results, including:

- The high prices of raw materials and non-control and the monopoly of raw materials by some traders.

- The negative impact of imports from abroad, which negatively affects the work of the two workshops. There are no schools that qualify the boys for craft work.

- There is no interest of the state in the two parties and no insurance and no pensions. The study also reached a number of recommendations, the most important of which are:

- The researcher is recommended to set up a government agency to monitor the prices and raw materials of handicrafts, heritage and heritage to meet the high prices of raw materials and prevent the monopoly of traders of raw materials.

- Interest in the establishment of educational institutions whose aim is to train and develop the skills of boys and craftsmen of traditional handicrafts and to encourage the boys to study and training.

- Include all workers in traditional handicrafts in the system of insurance, pensions and health and raise the standard of living.

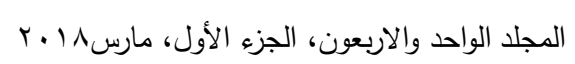

